\title{
Wing bone laminarity is not an adaptation for torsional resistance in bats
}

Andrew H Lee, Erin L. R. Simons

Torsional loading is a common feature of skeletal biomechanics during vertebrate flight. The importance of resisting torsional loads is best illustrated by the convergence of wing bone structure (e.g., long with thin walls) across extant bats and birds. Whether or not such a convergence occurs at the microstructural level is less clear. In volant birds, the humeri and ulnae often contain abundant laminar bony tissue in which primary circumferential vascular canals course concentrically about the long axis of the bone. These circumferential canals and the matrix surrounding them presumably function to resist the tissue-level shear stress caused by flight-induced torsion. Here, we assess whether or not laminar bone is a general adaptive feature in extant flying vertebrates using a histological analysis of bat bones. We sampled the humeri from six adult taxa representing a broad phylogenetic and body size range (6 - $1000 \mathrm{~g}$ ). Transverse thick sections were prepared from the midshaft of each humerus. Bone tissue was classified based on the predominant orientation of primary vascular canals. Our results show that humeri from bats across a wide phylogenetic and body size range do not contain any laminar bone. Instead, humeri are essentially avascular in bats below about $100 \mathrm{~g}$ and are poorly vascularized with occasional longitudinal to slightly radial canals in large bats. In contrast, humeri from birds across a comparable size range (40 - $1000 \mathrm{~g}$ ) are highly vascularized with a wide range in bone laminarity. Phylogenetically-informed scaling analyses reveal that the difference in vascularity between birds and bats is best explained by higher somatic relative growth rates in birds. The presence of wing bone laminarity in birds and its absence in bats suggests that laminar bone is not a necessary biomechanical feature in flying vertebrates and may be apomorphic to birds. 
$10 *$ Corresponding author

11 Andrew H. Lee

12 Department of Anatomy

13 Midwestern University

14 Glendale AZ 85308

15 USA

16 alee712@gmail.com

17 


\section{INTRODUCTION}

Flapping flight only evolved in three vertebrate clades: pterosaurs, birds, and bats. In each clade, the forelimb was modified into an airfoil using a different combination of skeletal elements and integument. Yet in these clades, the repeated evolution of proximal wing bones with large diameters and thin walls highlights similar biomechanical constraints to optimize bending and torsional (i.e., twisting) resistance (Currey \& Alexander, 1985; Cubo \& Casinos, 1998). In vivo demonstration of bone strains confirms substantial torsional loading in the humerus of a large fruit bat and the pigeon (Swartz, Bennett \& Carrier, 1992; Biewener \& Dial, 1995). Although generalization from limited interspecific sampling of in vivo bone strains warrants caution, consilience from bone geometry and kinetics suggests that amniotes evolved gross skeletal features to resist torsional loads during flapping flight (Swartz, Bennett \& Carrier, 1992; Biewener \& Dial, 1995).

The biomechanical influence of flapping flight may also govern organization at the histological level. One of the histological features of bone under investigation is the network of primary vascular canals, which are small channels containing blood vessels, loose connective tissue, and visceral nerves (Ross \& Pawlina, 2011). Primary vascular canals vary in orientation across the adult limb skeleton (Fig. 1) and are well-documented particularly in birds (e.g., de Margerie, 2002; de Margerie, Cubo \& Castanet, 2002; Skedros \& Hunt, 2004; de Margerie et al., 2005; Simons \& O’Connor, 2012). In particular, primary vascular canals oriented circumferentially to form laminar bone (Fig. 1A) are abundant in the midshaft humerus. Because this location is hypothesized to experience elevated torsional loading during flight, the presence of laminar bone in the humerus may relate to a biomechanical function (de Margerie, 2002; de Margerie et al., 2005). Wing shape may also influence the proportion of laminar bone in the humerus (laminarity index sensu de Margerie, 2002) presumably because broad wings produce greater twisting moments (torques) than narrow wings (de Margerie et al., 2005; Simons \& O’Connor, 2012). Together, these findings suggest that laminar bony tissue may 
42 be a biomechanical adaptation to flight-induced torsional loads at least in birds (de Margerie, 2002; de

43 Margerie et al., 2005).

The convergence of flapping flight in bats (Norberg, 1994) presents an opportunity to address the extent of laminar bone as a general histological response to flight-induced torsion. Yet, there are few studies detailing bone histology in bats. The most taxonomically comprehensive of these is limited to the femur, which generally consists of lamellar bony tissue and shows size-dependent vascularity; large-bodied taxa have poorly vascularized femora with predominantly longitudinal primary vascular canals, whereas small-bodied taxa have avascular femora (Foote, 1916). At least for three taxa, various proximal wing elements are also poorly vascularized or avascular (Enlow \& Brown, 1958; de Ricqlès et al., 1991; Papadimitriou, Swartz \& Kunz, 1996; Bennett \& Forwood, 2010).

However, data from the humerus are limited altogether to a single small-bodied species of undetermined taxonomic identity (Enlow \& Brown, 1958). Here, we present a more comprehensive assessment of the histology of bat humeri to test for the presence of laminar bony tissue. As a basis for comparison, we also present histology of bird humeri from available volant taxa. If patterns of bone laminarity in bats and birds converge upon each other, then there may be a fundamental torsionresisting constraint at the tissue level.

Alternatively, the humeri of bats may be avascular or poorly vascularized. To test whether bone vascularity (or its absence) influences whole-bone torsional rigidity, we compare how polar section modulus (a measure of cortical distribution) scales with body size in bats and birds. Because the proximal wing elements of volant amniotes are generally thin-walled (Currey \& Alexander, 1985; Swartz, Bennett \& Carrier, 1992), we expect the torsional rigidity of bat and bird humeri to scale similarly in spite of potential differences in bone vascularity. This would suggest that adaptation of the humerus to flight-induced torsion is principally in bone shape rather than in tissue-level organization. 
Other factors besides biomechanics may contribute to differences in bone vascularity between

66 bat and bird humeri. As conduits for blood vessels (Ross \& Pawlina, 2011), vascular canals may

67 promote molecular exchange (Seymour et al., 2012). Therefore, we expect bone vascular patterns to

68 correlate directly with physiological factors that depend on molecular exchange. Two such factors that

69 have received attention are somatic rates of active (field) metabolism (e.g., Seymour et al., 2012) and

70 growth (e.g., Amprino, 1947; de Margerie, Cubo \& Castanet, 2002; Williams et al., 2004). To test

71 which of these two factors may account for differences in bone vascularity, we look for corresponding

72 differences in chiropteran and avian scaling of field metabolic rate and somatic maximum growth rate.

73 By disentangling mechanical, metabolic, and growth-related influences on the histology of bat and bird

74 humeri, we gain insight into the factors that govern skeletal variation in flying vertebrates more

75 generally. 
MATERIALS \& METHODS

\section{Sampling and histology}

We collected humeri from six extant chiropteran taxa (Table 1). The sampled taxa represent both major clades of bats (Teeling et al., 2005; Hutcheon \& Kirsch, 2006; Tsagkogeorga et al., 2013), Yangochiroptera (Vespertilioniformes) and Yinpterochiroptera (Pteropodiformes) and span three orders of magnitude in body mass $(6-1000 \mathrm{~g})$, representing nearly the entire size range found in bats (Norberg \& Norberg, 2012). Whereas the sampled bats vary in specific feeding behaviors (e.g., insectivore, frugivore, piscivore, nectarivore), they have relatively similar wing shapes (aspect ratios $\approx$ 6-9: Norberg \& Rayner, 1987). We also sampled several avian taxa with broad wing shape similar to the bats as part of our ongoing studies on wing bone laminarity and include some of those data here for comparison (Table 1). To minimize the confounding effects of ontogeny on bone histology (e.g., Padian, 2013), only skeletally mature specimens were sampled. Prior to histological sampling, length of each humerus was measured (Table 1), and three-dimensional replicas were produced by molding and casting (Lamm, 2013).

A mid-diaphyseal block was removed from each humerus using a rotary tool (Dremel 4000). The following steps are summarized in Table S1. Blocks of bone were fixed under vacuum in $10 \%$ neutral buffered formalin. After fixation, the blocks were successively dehydrated using 70\%, 85\%, and $100 \%$ ethanol under vacuum. The blocks were cleared under vacuum with a xylene-substitute (Histo-clear, National Diagnostics). Infiltration of the blocks was performed by vacuum-impregnation in a series of methyl methacrylate (MMA) resins (Osteo-Bed, Polysciences Inc.). To complete embedding, each bone block was transferred to an air-tight glass vial filled with MMA. Vials were placed in a bead bath set to $32^{\circ} \mathrm{C}$ and allowed 48 hours to fully harden.

The plastic-embedded specimens were released from the glass vials, and two transverse $700-\mu \mathrm{m}$ wafers were cut from each specimen at midshaft using a precision saw (Isomet 1000, Buehler). Wafers 
100 were glued (2-Ton epoxy, Devcon) to frosted glass slides and manually ground (Metaserv 250,

101 Buehler) to $100 \pm 10 \mu \mathrm{m}$.

102

103 Imaging

Whole thick sections were imaged without coverslips under non-polarized light to measure

105 vascular canal orientation as well as under circularly polarized light to distinguish between parallel-

106 fibered and woven bone matrix (Fig. S1 \& S2). After polarized light microscopy was performed,

107 sections were acid-etched and stained with a heated solution of toluidine blue (Eurell \& Sterchi, 1994).

108 This particular preparation of toluidine blue does not require the removal of embedding resin and

109 works on thick sections already mounted to slides. Because this base-like metachromatic dye

110 highlights features rich in acidic or anionic components such as cement lines of secondary osteons,

111 medullary bone, and hyaline cartilage, we were able to quickly identify and exclude vascular canals of

112 secondary osteons from further analysis (Fig. S3 \& S4). Stained and unstained sections were imaged

113 using a motorized light microscope (Ni-U, Nikon) with a strain-free long-working distance objective

114 (10x Plan Fluor: numerical aperture of 0.3 , resolvable size $\approx 1 \mu \mathrm{m}$ ). Focus and stitching of histological

115 montages were controlled by software (NIS Elements D, Nikon). The montages were sharpened using

116 Photoshop (CS5, Adobe) with the "Unsharp Mask" filter set at $10 \mathrm{px}$ and are high resolution $(2.1 \mu \mathrm{m}$

117 per pixel). In accordance with major grant funding agencies and to promote data transparency, the

118 montages are freely accessible as interactive digital slides at the Paleohistology Repository (Lee \&

119 O'Connor, 2013: http://paleohistology.appspot.com). After imaging, a standard glass coverslip was

120 mounted (Permount, Fisher Scientific) to each physical slide to arrest long-term cracking of

121 undecalcified bone sections.

\section{Assessing bone laminarity}


A method to measure primary vascular canal orientation was first proposed by de Margerie

125 (2002) and later used by subsequent studies (e.g., Lee, 2004; Skedros \& Hunt, 2004; Cubo et al., 2005;

126 Simons \& O’Connor, 2012). Although we recognize that this method was modified to offer greater

127 descriptive precision (de Boef \& Larsson, 2007; Lee, 2007), the added precision is excessive for the bat

128 dataset because canal orientation is unambiguous. Therefore, we used the method by de Margerie

129 (2002) with slight modifications to improve throughput.

Using Photoshop, we divided the cortex of each thick section into octants and extracted the four

131 cortical octants representing cardinal anatomical positions (bats: anterior, posterior, lateral, and medial;

132 birds: cranial, caudal, dorsal, and ventral). We avoided measurement below the plane of section (i.e.,

133 the polished surface) and only measured the most in-focused portions of each primary vascular canal.

134 If a canal branched, it was separated into individual canals at the node. Vascular canals of secondary

135 osteons were excluded from further analysis. Using ImageJ, an ellipse was fitted inside each canal, and

136 aspect ratio and orientation of the major axis relative to the periosteal surface were measured. To

137 determine canal orientation from the aspect ratio and major axis of the ellipse, we followed criteria

138 proposed by de Margerie (2002). The criteria are summarized as follows: (1) longitudinal canals have

139 an aspect ratio of less than 3 (Fig. 1B); (2) circumferential canals have major axes oriented $0^{\circ} \pm 22.5^{\circ}$

140 relative to the nearest tangent line drawn at the periosteal surface (Fig. 1A); (3) radial canals have

141 major axes oriented $90^{\circ} \pm 22.5^{\circ}$ relative to the nearest tangent line drawn at the periosteal surface (Fig.

142 1C); and (4) all remaining canals are oblique.

143 In most sections, the curvature of the periosteal surface means that the tangent line needed to

144 measure circumferential and radial canals changes across the cortical octant. The repeated referencing

145 of each canal to a variable periosteal tangent line is time-consuming and increases the likelihood of

146 measurement error. We standardized the tangent line and thereby increased the throughput of canal

147 measurement by uncurving each cortical octant relative to the periosteal surface using the "Straighten" 
148 function in ImageJ (1.49b, National Institutes of Health, USA). Once a cortical quadrant is

149 "straightened," the periosteal surface is aligned with the horizontal (Figs. 2 \& 3) and a constant

150 reference line is established. To assess the extent of image deformation on canal orientation, we

151 overlaid a graphical layer containing known test angles relative to the periosteal surface and circular

152 profiles prior to straightening. On average, image deformation is acceptable; test angles deviate no

153 more than 5 degrees from their original values, and circular profiles maintain aspect ratios between

$1541.00-1.17$. At least for the currently sampled bones with relatively thin cortices, the "Straighten"

155 function preserves original orientation data.

156 We calculated the proportion of circumferential canals for sections with a non-zero number of

157 circumferential canals (laminarity index sensu de Margerie, Cubo \& Castanet, 2002) using the Wilson

158 estimate for a population proportion and confidence interval. This estimate accounts for bias from

159 small sample sizes (Samuels \& Witmer, 1999). Published laminarity index values from six individuals

160 of broad-winged birds were included for comparison (Simons \& O’Connor, 2012).

161

\section{Compilation of relative growth and field metabolic rates}

163

164 literature (Zullinger et al., 1984; Kunz \& Stern, 1995; Starck \& Ricklefs, 1998; Koehler \& Barclay,

165 2000; Kunz \& Hood, 2000; McLean \& Speakman, 2000; Jin et al., 2012). For each species, two values

166 were calculated at the age of growth inflection (see equations in: Lee et al., 2013): (1) maximum

167 growth rate and (2) body mass (Table S3). Maximum growth rate is strongly correlated with mass

168 (Case, 1978). To account for the confounding effect of size on maximum growth rate, relative growth

169 rate (RGR) was used instead and was calculated as the ratio of maximum growth rate and mass at

170 inflection (e.g., Cooper et al., 2008). 
171

172

173

174

175

176

177

178

179

180

181

182

183

184

185

186

187

188

189

190

191

192

193

194

Field metabolic rates and mass representing species-averages of 14 bats and 86 birds (Table S4) were compiled from previous studies (Delorme \& Thomas, 1999; Geiser \& Coburn, 1999; Nagy, Girard \& Brown, 1999; Voigt, Kelm \& Visser, 2006; Hudson, Isaac \& Reuman, 2013). Most of these studies used the "doubly labeled water" method (see review: Nagy, 2005) in free-ranging individuals to estimate field metabolic rate (FMR). In contrast, the study by Delorme et al. (1999) estimated FMR from individuals of Artibeus jamaicensis and Rousettus aegyptiacus that were allowed to feed freely but not to fly. While confined, these individuals did not experience major locomotor costs associated with flight or weight gain. Yet, FMR estimates from the confined bats are close to mean values expected in free-ranging bats of comparable size. Therefore, the inclusion of the FMR estimates from these confined bats is justified. Moreover, they are needed to increase the modest sample size and phylogenetic breadth of the chiropteran FMR dataset. To remove the confounding effects of size on FMR, estimates were standardized by mass. The resulting values of mass-specific FMR and RGR were $\log 10$-transformed before use in regression analyses.

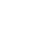

\section{Cross-sectional geometry}

In Photoshop, we prepared cortical bone profiles of the humeral sections by tracing the periosteal and endosteal surfaces of each histological montage and filling the area of the cortical bone white and the background black. To supplement our sample, we included a published cortical bone profile of the humerus from the bat Myotis myotis (Meier et al., 2013) as well as profiles scanned by microCT representing nine avian taxa (Simons, Hieronymus \& O’Connor, 2011; ELR Simons unpublished data). Cortical bone profiles were processed using BoneJ for ImageJ to calculate the cross-sectional geometric parameters of each specimen (Table 1). For this study, we primarily focused on the polar section modulus $\left(\mathrm{Z}_{\mathrm{p}}\right)$, which is an estimate of torsional rigidity and average bone bending rigidity (Ruff, 2002). The torsional rigidity of a long bone is related to an applied torque (force and 
195 cross-sectional radius), material properties, length, and the geometric property called the torsion

196 constant. When the cross-sectional profile of a long bone is nearly circular, the torsion constant is

197 equal to the polar moment of area (J) (Craig, 2000). The same is true for $Z_{p}$, which is $J$ standardized by

198 the cross-sectional radius (i.e., the moment arm). Because $Z_{p}$ is a better estimate of torsional rigidity

199 when the transverse section of a bone is circular, we used a shape ratio $\left(I_{\max } / I_{\min }\right.$ : Table $\left.S 2\right)$ to

200 determine the degree of circularity (Daegling, 2002). Caution is recommended when a section is

201 strongly elliptical, but even in a non-circular section, $Z_{p}$ can still be a heuristic estimate of overall

202 torsional and bending rigidity (Ruff et al., 2013). To compare the torsional rigidity of humeri across

203 bats and birds of different body and wing sizes, we regressed $Z_{p}$ against the product of body mass and

204 total length of the humerus (e.g., Ruff, 2000; Stock \& Shaw, 2007; Young, Fernández \& Fleagle,

205 2010). Specimens without associated body mass data were assigned published mean values for the

206 species (Kunz \& Stern, 1995; Savage et al., 2004; Dunning, 2008; de Magalhaes et al., 2009). Values

207 were $\log 10$-transformed before use in regression analysis.

\section{Phylogenetically informed scaling analyses (PISA)}

Ordinary least squares (OLS) regression, which is commonly used in comparative scaling

211 analyses, assumes that data points are statistically independent. This assumption, however, often is

212 violated in comparative datasets because data points of closely related species are more likely to be

213 similar to each other than to those of distantly related species. By failing to account for this

214 phylogenetic pseudoreplication, an OLS analysis can either detect a significant trend where none exists

215 (i.e., confidence intervals are overly narrow) or incorrectly specify the directionality of a significant

216 trend (Nunn \& Barton, 2001).

217 Recent advances in mammalian and avian systematics make it possible to incorporate

218 phylogenetic information into scaling analyses of polar section modulus $\left(Z_{p}\right)$, relative growth rate 
219 (RGR), and mass-specific field metabolic rate (FMR). The most recent phylogenies of bats

220 (Agnarsson et al., 2011; Tsagkogeorga et al., 2013) and supertree of birds (Davis \& Page, 2014) either

221 present a time-calibrated phylogeny of a small subset of sampled taxa or are completely uncalibrated to

222 geological time. Therefore, we used older time-calibrated supertrees of mammals (Bininda-Emonds et

223 al., 2007) and birds (Jetz et al., 2012). Both supertrees were pruned to match our taxonomic sampling

224 of bats and birds, respectively, in R (R Development Team, 2014) with the "ape" package (Paradis,

225 Claude \& Strimmer, 2004). Polytomies were broken and replaced with zero-length branches (Martins

$226 \&$ Hansen, 1996).

We performed phylogenetically informed scaling analyses (PISA) in a phylogenetic generalized

228

229

230

231

232

233

234

235

236

237

238

239

240

241

least-squares (PGLS) framework (Martins \& Hansen, 1997; Garland \& Ives, 2000) as implemented by the "ape" package. Variance-covariance matrices were calculated to approximate Brownian motion as well as an Orstein-Uhlenbeck model of evolution (Martins \& Hansen, 1997) using "corsBrownian" and “corsMartin", respectively. Variance-covariance structures were passed into the R package "nlme", and regressions were fit by maximizing the restricted log-likelihood. Model I regression was used because model II regression tends to overcorrect when a dataset does not have enough within-species replication to estimate error variances (Carroll \& Ruppert, 1996; Carroll et al., 2006). The resulting OLS and PGLS model I regressions were compared on the basis of three criteria. First, we tested each trait for the presence of significant phylogenetic signal (Blomberg \& Garland, 2002) using the R package "picante" (Kembel et al., 2010). If we could not detect significant phylogenetic signal (this does not imply the absence of phylogenetic signal in the trait), we selected the OLS model. Second, we assessed the residual plots of each model for randomness to assess the appropriateness of a linear model for log-transformed data. Third, we evaluated the remaining models and chose the one with the lowest value of the corrected Akaike's Information Criterion (AIC $\mathrm{c}_{\mathrm{c}}$ : Hurvich \& Tsai, 1989). 


\section{RESULTS AND DISCUSSION}

243

\section{Bat humeri do not consist of laminar bone}

Across both major clades of bats, Vespertilioniformes and Pteropodiformes, small- to mediumbodied taxa $(\sim 6-100 \mathrm{~g})$ have essentially avascular humeri (Fig. 2A $-\mathrm{E})$. In contrast to the avascularity found in smaller forms, the humerus of the large-bodied pteropodiform Pteropus vampyrus ( $1000 \mathrm{~g}$ : Kunz \& Jones, 2000) is sparsely vascularized (Fig. 2F). Where present, primary vascular canals have a prominent longitudinal to slightly radial orientation, which is inconsistent with the hypothesis that wing bones habitually loaded in torsion contain predominantly circumferential canals. Indeed, laminar bone is completely absent in the humeri of sampled bats (Table 1). Because the sample represents a wide range in phylogeny, feeding behavior, and body size, the likelihood is strong that bat humeri do not contain laminar bone.

The vascular dichotomy between small- and large-bodied bats extends beyond the humerus to other limb elements. In the radius, a small bat (of undetermined taxonomic identity: Enlow \& Brown, 1958) shows avascular tissue, whereas a large bat (Pteropus poliocephalus at $750 \mathrm{~g}$ : Bennett \&

Forwood, 2010) has weakly vascularized bone with longitudinal canals. Moreover, in the femur, vascularized bone with longitudinal to slightly radial canals appears restricted to species of large body size such as those of Pteropus [i.e., molossinus, aldabrensis, lepidus (cf. hypomelanus: Jones \& Kunz, 2000), and poliocephalus] (Foote, 1916). The histology of the femur is remarkably similar to that of the humerus in bats of comparable class size, a pattern seen in some avian species as well (de Margerie, 2002; Marelli \& Simons, 2014).

\section{Vascularity of bat humeri relates to a threshold in adult body size}

Although poorly vascularized, the humerus of Pteropus vampyrus is still more vascularized than those of the other bats in the sample. This difference in vascularity seems unrelated to wing 
266 shape. Noctilio leporinus and P. vampyrus have similar wing aspect ratios (9.0 and 8.4, respectively:

267 Norberg \& Rayner, 1987) yet differ in vascularity of the humerus (Figs. 2D \& F). Feeding behavior 268 also is an unlikely explanation. Frugivory characterizes the primary feeding behavior of both 269 Rousettus leschenaultii and P. vampyrus (Norberg \& Rayner, 1987), but they have humeri with 270 contrasting vascularity (Figs. 2E \& F).

271 Across amniotes, maximum somatic growth rates (Case, 1978) and field metabolic rates (Nagy, 272 2005) are strongly dependent on body mass. Consequently, the increased bone vascularity in large273 bodied bats compared to small-bodied bats may reflect rapid somatic growth rate, elevated field 274 metabolic rate, or large size. When the confounding influence of size on somatic growth and field 275 metabolic rate are accounted for (i.e., a relative growth rate and mass-specific field metabolic rate, 276 respectively), large-bodied bats have relatively low growth and field metabolic rates compared to 


\section{Bird humeri have variable bone laminarity despite habitual flight-induced torsion}

In contrast to bats, volant birds sampled across a similar body size range $(40-1000 \mathrm{~g})$ have noticeably vascularized humeri (Fig. 3). Overall, primary vascular canal orientation as represented by the laminarity index is moderately circumferential (Table 1). However, low laminarity (0.063) in the humerus of Columba livia (Fig. 3E) is counterintuitive given that the humerus in this species is known to experience high torsional loads during flight; torsional shear strains are 1.5 times greater than longitudinal strains (Biewener \& Dial, 1995). This result weakens the correlation between laminar bone and torsional loading and suggests the need for increased sampling and reassessment by future studies. Put together, low laminarity in a pigeon humerus, ubiquity of essentially avascular humeri in small- to medium-bodied bats, and longitudinal orientation of canals in the humerus of one of the largest species of bat suggest that laminar bone is not a necessary biomechanical adaptation in flying vertebrates.

\section{Adult body size does not explain vascular dichotomy between bats and birds}

Bats and birds do not share the same adult size threshold for bone vascularity. Avian taxa as small as $48 \mathrm{~g}$ (Phalaenoptilus nuttallii: Fig. 3A) contain abundant vascular canals in the humerus in striking contrast to bats of comparable size (e.g., Phyllostomus discolor and Noctilio leporinus: Fig. 2C \& D). Furthermore, large body size does not reduce the vascular disparity between the humeri of bats and birds. At approximately 1000 g, Pteropus vampyrus (Fig. 2F) has a humerus with far fewer canals (let alone circumferentially oriented ones) than Tinamus major (Fig. 3I). Clearly, adult body size is not responsible for the strong dichotomy in vascularity between bat and bird humeri.

\section{Torsional rigidity does not explain vascular dichotomy between bats and birds}


314 have similar cross-sectional geometry. Specifically, we are unable to reject the possibility that

315 chiropteran and avian polar section modulus $\left(\mathrm{Z}_{\mathrm{p}}\right)$ scales isometrically with the product of mass and

316 humeral length (Fig. 6). Scaling relationships based on OLS and PGLS regression are

317 indistinguishable (Table 4) probably because the sample size of seven bats and 18 birds is too small for

318 the effects of phylogeny to be significant. Of course, greatly increased sampling may improve

319 detection of differences in how $Z_{p}$ scales with size between chiropteran and avian humeri. There is,

320 however, independent evidence to support the interpretation that some mechanical properties of bat and 321 bird humeri really are similar.

At least for the humerus, tissue density (Dumont, 2010) and mineral content (Currey, 1984;

323 Papadimitriou, Swartz \& Kunz, 1996; Swartz \& Middleton, 2008) are relatively unspecialized across

324 birds and mammals, bats included. This similarity of material properties in volant and non-volant taxa

325 suggests that specializations in shape may be the primary means by which bat and bird humeri resist

326 flight-induced torsion (Dumont, 2010). Indeed, relative cortical thickness of humeri is thinner in bats

327 than in non-volant mammals and converges independently on the relative cortical thickness observed in

328 birds (Currey \& Alexander, 1985; Swartz, Bennett \& Carrier, 1992). Those previous findings together

329 with our results on cross-sectional geometry suggest that the torsional rigidity of bat and bird humeri

330 may be convergent adaptations to loads imposed by flapping flight (Currey \& Alexander, 1985;

331 Swartz, Bennett \& Carrier, 1992; Biewener \& Dial, 1995). Although torsional rigidity of the humerus

332 appears relatively constrained in bats and birds of comparable size, bone vascularity is strongly

333 divergent. This suggests that the biomechanical factors constraining mineral content and cortical

334 geometry in bats and birds have negligible impact on bone vascularity. 
The vascular dichotomy in the chiropteran and avian humerus is not related to differences in

338

339

340 mass-specific daily energy expenditure. Note that the daily estimates include but are not limited to the

costs of maintenance (basal metabolism) as well as of flight, which is metabolically expensive but may not be equivalent in bats and birds given differences in flight efficiency, kinematics, and ecology found in small-bodied taxa (Winter \& von Helversen, 1998; Voigt \& Lewanzik, 2011; Muijres et al., 2012). Without a more thorough phylogenetic sampling of the costs of flight in bats, we take the circumspect but still ecologically relevant approach with mass-specific field metabolic rate (FMR). OLS and PGLS regressions recover significant negative trends in mass-specific FMR that are statistically indistinguishable between bats and birds (Table 2; Fig. 4). These results are consistent with preliminary work based on the OLS regression of maximal metabolic rate (Schmidt-Nielsen, 1984, p. 158) and suggest the possibility that active bats and birds at a given size have similar daily energy expenditure per unit mass. Yet, the humeri of bats and birds have strikingly different vascularity contrary to predictions (Fig. 4). This inconsistency suggests that mass-specific FMR is not a strong contributing factor to the vascular dichotomy in bat and bird humeri.

\section{Somatic growth rate may explain vascular dichotomy between bats and birds}

Unlike torsional rigidity and mass-specific FMR, somatic measures of relative growth rate (RGR) may account for the vascular dichotomy between bat and bird humeri. Consilience from OLS and PGLS regressions (Table 3) strongly suggests that body mass in bats, on average, grows about four times slower than in birds of comparable size. This difference in relative growth rate is consistent with predictions from Amprino's Rule (Amprino, 1947); relatively rapid-growing birds express well vascularized humeri, whereas relatively slow-growing bats express avascular to poorly vascularized humeri (Fig. 5). A potential criticism of these comparisons is that somatic RGR is a crude approximation of local expressions of growth. For example, growth rates of periosteal bone differs 
361 across the skeleton (e.g., de Ricqlès et al., 1991; Castanet et al., 2000; de Margerie et al., 2004).

362 Indeed, the wings of volant taxa may grow disproportionately faster than the rest of the body as

363 suggested by positive allometry in wing bone length from a small ontogenetic sample of bats and

364 volant birds (e.g., Carrier \& Leon, 1990; Cretekos et al., 2008). Cursory examination of available data

365 on the growth in 32 species of bats, however, reveals that the logistic growth constant $\mathrm{K}$ (relative

366 growth rate) of forearm (radius) length is slightly greater than but comparable to that of body mass

367 (Kunz \& Hood, 2000). The relative growth rate of the chiropteran humerus in these species is not

368 reported, but it is presumably similar to the radius. In avian studies, growth of proximal wing elements

369 are not typically reported, but if growth is positively allometric like that in the California gull (Carrier

$370 \&$ Leon, 1990), then somatic RGR can still be heuristic as a minimum estimate of growth in the

371 humerus; that is, the actual growth disparity between bat and bird humeri may be at least what is

372 implied here (Fig. 5). Therefore, a tentative but reasonable conclusion is that the vascular dichotomy

373 between bat and bird humeri of comparably-sized individuals primarily reflects differences in relative

374 growth rate. 
375

376

377

378

379

380

381

382

383

384

385

386

387

388

390

391

392

393

\section{CONCLUSIONS}

Avascular to poorly vascularized humeri of bats suggest that adaptation to flight need not involve laminar bone. Indeed, despite poor vascularity, bat humeri have potentially equivalent crosssectional rigidity to torsion as bird humeri. In bats, bone shape rather than tissue-level organization may be the principal mechanism of specialization to loads. The humerus is only vascular, albeit sparsely, in adult bats greater than $100-200 \mathrm{~g}$. This contrast in bone vascularity between small and large bats cannot be explained by feeding behavior, wing aspect ratio, mass-specific field metabolic rate, or somatic relative growth rate suggesting that vascular canals may be necessary beyond a sizethreshold to supplement canaliculi in nutrient and waste exchange. Surprisingly, potentially similar daily metabolic expenditure in active bats and birds of comparable size need not involve highly vascularized humeri; poor bone vascularity in bats appears sufficient. The vascular disparity between bat and bird humeri may be related to differences in somatic relative growth rate in which bats grow approximately four times slower than comparably-sized birds. Therefore, bats may grow too slowly to form laminar bone.

At this time, however, we cannot assess whether laminar bone is an expression of early juvenile growth or a direct response to flight loads in the taxa where it evolved (namely in birds). Future investigations (some of which are already in progress) should focus on when laminar bone forms during ontogeny and how it responds to evolutionary acquisitions or losses of flight. 


\section{ACKNOWLEDGEMENTS}

395 We thank K Ezell for assistance in molding, casting, embedding, and imaging of specimens.

396 We also thank R Ourfalian for sharing some data from his ongoing project involving bone laminarity in 397 the pigeon wing. J Kamilar provided consultation on the implementation of phylogenetically informed 398 statistics. The following colleagues facilitated loans of specimens under their care: M Bucci, G 399 Bradley, M Hall, D Steadman, and T Weber. Constructive reviews by two anonymous reviewers, J 400 Botha-Brink, and S Swartz improved the narrative of the manuscript. Finally, we would like to thank 401 the late D Enlow, whose seminal works in comparative hard tissue biology continues to inspire us and 402 future generations.

403 
404

405

406

407

408

409

410

411

412

413

414

415

416

417

418

419

420

421

422

423

424

425

426

\section{REFERENCES}

Agnarsson I, Zambrana-Torrelio C, Flores-Saldana N, Nat-Collado L. 2011. A time-calibrated specieslevel phylogeny of bats (Chiroptera, Mammalia). PLoS Currents 1:e2157-3999.

Amprino R. 1947. La structure du tissu osseux envisagee comme expression de differences dans la vitesse de l'accroissement. Archives de Biologie 58:315-330.

Bennett MB, Forwood MR. 2010. Histomorphometric changes in the wing bones of the fruit bat, Pteropus poliocephalus, (Megachiroptera: Pteropidae [sic Pteropodidae]) in relation to increased bone strain and the failure of a good (?) hypothesis. Australian Zoologist 35:341-348.

Biewener AA, Dial KP. 1995. In vivo strain in the humerus of pigeons (Columba livia). Journal of Morphology 225:61-75.

Bininda-Emonds ORP, Cardillo M, Jones KE, MacPhee RDE, Beck RMD, Grenyer R, Price SA, Vos RA, Gittleman JL, Purvis A. 2007. The delayed rise of present-day mammals. Nature 446:507512.

Blomberg SP, Garland T. 2002. Tempo and mode in evolution: phylogenetic inertia, adaptation and comparative methods. Journal of Evolutionary Biology 15:899-910.

De Boef M, Larsson HCE. 2007. Bone microstructure: quantifying bone vascular orientation. Canadian Journal of Zoology 85:63-70.

De Buffrénil V, Houssaye A, Böhme W. 2008. Bone vascular supply in monitor lizards (Squamata: Varanidae): Influence of size, growth, and phylogeny. Journal of Morphology 269:533-543.

Carrier D, Leon LR. 1990. Skeletal growth and function in the California gull (Larus californicus). Journal of Zoology 222:375-389.

Carroll RJ, Ruppert D, Stefanski LA, Crainiceanu CM. 2006. Measurement error in nonlinear models: a modern perspective. Boca Raton: CRC Press. 
427 Carroll RJ, Ruppert D. 1996. The use and misuse of orthogonal regression in linear errors-in-variables $428 \quad$ models. The American Statistician 50:1-6.

429 Case TJ. 1978. On the evolution and adaptive significance of postnatal growth rates in the terrestrial 430 vertebrates. Quarterly Review of Biology 53:243-282.

431 Castanet J, Curry-Rogers K, Cubo J, Boisard J-J. 2000. Periosteal bone growth rates in extant ratites 432 (ostriche [sic] and emu). Implications for assessing growth in dinosaurs. Comptes Rendus de l'Academie des Sciences Serie III Sciences de la Vie 323:543-550.

436

Cooper LN, Lee AH, Taper ML, Horner JR. 2008. Relative growth rates of predator and prey dinosaurs reflect effects of predation. Proceedings of the Royal Society B 275:2609-2615.

Craig RR Jr. 2000. Mechanics of Materials. New York: John Wiley \& Sons, Inc.

Cretekos CJ, Wang Y, Green ED, NISC Comparative Sequencing Program, Martin JF, Rasweiler JJ, Behringer RR. 2008. Regulatory divergence modifies limb length between mammals. Genes \& Development 22:141-151.

Cubo J, Ponton F, Laurin M, de Margerie E, Castanet J. 2005. Phylogenetic signal in bone microstructure of sauropsids. Systematic Biology 54:562-574.

Cubo J, Casinos A. 1998. The variation of the cross-sectional shape in the long bones of birds and mammals. Annales des Sciences Naturelles-Zoologie et Biologie Animale 19:51-62.

Currey JD. 1984. The mechanical adaptations of bones. Princeton: Princeton University Press.

Currey JD, Alexander RM. 1985. The thickness of the walls of tubular bones. Journal of Zoology 1985:453-468.

Daegling DJ. 2002. Estimation of torsional rigidity in primate long bones. Journal of Human Evolution 43:229-239.

Davis KE, Page RDM. 2014. Reweaving the tapestry: a supertree of birds. PLoS Currents Tree of Life 1. 
451 Delorme M, Thomas DW. 1999. Comparative analysis of the digestive efficiency and nitrogen and

452

453

454

455

456

457

458

459

460

461

462

463

464

465

466

467

468

469

470

471

472

473

474

energy requirements of the phyllostomid fruit-bat (Artibeus jamaicensis) and the pteropodid fruit-bat (Rousettus aegyptiacus). Journal of Comparative Physiology B 169:123-132.

Dumont ER. 2010. Bone density and the lightweight skeletons of birds. Proceedings of the Royal Society B 277:2193-2198.

Dunning JB Jr. (ed.) 2008. CRC Handbook of Avian Body Masses. Boca Raton: CRC Press.

Enlow DH, Brown SO. 1958. A comparative histological study of fossil and recent bone tissues. Part III. Mammalian bone tissues. General discussion. Texas Journal of Science 10:187-230.

Eurell JAC, Sterchi DL. 1994. Microwaveable toluidine blue stain for surface staining of undecalcified bone sections. Journal of Histotechnology 17:357-359.

Foote JS. 1916. A contribution to the comparative histology of the femur. Smithsonian Contributions to Knowledge 35:1-231.

Garland T, Ives AR. 2000. Using the past to predict the present: confidence intervals for regression equations in phylogenetic comparative methods. American Naturalist 155:346-364.

Geiser F, Coburn DK. 1999. Field metabolic rates and water uptake in the blossom-bat Syconycteris australis (Megachiroptera). Journal of Comparative Physiology B 169:133-138.

Hudson LN, Isaac NJB, Reuman DC. 2013. The relationship between body mass and field metabolic rate among individual birds and mammals. Journal of Animal Ecology 82:1009-1020.

Hurvich CM, Tsai C-L. 1989. Regression and time series model selection in small samples. Biometrika 76:297-307.

Hutcheon JM, Kirsch JAW. 2006. A moveable face: deconstructing the Microchiroptera and a new classification of extant bats. Acta Chiropterologica 8:1-10.

Jetz W, Thomas GH, Joy JB, Hartmann K, Mooers AO. 2012. The global diversity of birds in space and time. Nature 491:444-448.

Peer] reviewing PDF | (v2014:07:2454:2:1:NEW 9 Feb 2015) 
475 Jin L, Bo L, Sun K, Liu Y, Ho JP, Feng J. 2012. Postnatal growth and age estimation in Marshall's 476 Horseshoe Bat, Rhinolophus marshalli. Acta Chiropterologica 14:105-110.

477 Jones DP, Kunz TH. 2000. Pteropus hypomelanus. Mammalian Species 639:1-6.

478 Kembel SW, Cowan PD, Helmus MR, Cornwell WK, Morlon H, Ackerly DD, Blomberg SP, Webb CO. 2010. Picante: $\mathrm{R}$ tools for integrating phylogenies and ecology. Bioinformatics $26: 1463-$ 1464.

481

482

483

484

485

486

487

488

489

490

491

492

493 494 495 496 497 cinereus). Journal of Mammalogy 81:234-244.

Kunz TH, Hood WR. 2000. Parental care and postnatal growth in the Chiroptera. In: Reproductive Biology of Bats. San Diego: Academic Press, 415-468.

Kunz TH, Jones DP. 2000. Pteropus vampyrus. Mammalian Species 642:1-6.

Kunz TH, Stern AA. 1995. Maternal investment and post-natal growth in bats. Symposium of the Zoological Society of London 67:123-138.

Lamm E-T. 2013. Preparation and sectioning of specimens. In: Padian K, Lamm E-T eds. Bone Histology of Fossil Tetrapods: Advancing Methods, Analysis, and Interpretation. Berkeley, California: University of California Press, 55-160.

Lee AH. 2004. Histological organization and its relationship to function in the femur of Alligator mississippiensis. Journal of Anatomy 204:197-207.

Lee AH. 2007. Interplay between growth and mechanics in the evolution of bone microstructure in dinosaurs. Ph.D. dissertation Thesis. Berkeley, California: University of California, Berkeley.

Lee AH, Huttenlocker AK, Padian K, Woodward HN. 2013. Analysis of growth rates. In: Padian K, Lamm E-T eds. Bone Histology of Fossil Tetrapods: Advancing Methods, Analysis, and Interpretation. Berkeley, California: University of California Press, 217-251. 
498 Lee AH, O'Connor PM. 2013. Bone histology confirms determinate growth and small body size in the noasaurid theropod Masiakasaurus knopfleri. Journal of Vertebrate Paleontology 33:865-876.

500 De Magalhaes JP, Budovsky A, Lehman G, Costa J, Li Y, Fraifeld V, Church GM. 2009. The Human Aging Genomic Resources: online databases and tools for biogerontologists. Aging Cell 8:65-

503 72.

Marelli CA, Simons ELR. 2014. Microstructure and cross-sectional shape of limb bones in Great Horned Owls and Red-Tailed Hawks: how do these features relate to differences in flight and hunting behavior? PLOS ONE 9:e106094.

De Margerie E. 2002. Laminar bone as an adaptation to torsional loads in flapping flight. Journal of Anatomy 201:521-526.

De Margerie E, Robin J-P, Verrier D, Cubo J, Groscolas R, Castanet J. 2004. Assessing a relationship between bone microstructure and growth rate: a fluorescent labelling study in the king penguin chick (Aptenodytes patagonicus). Journal of Experimental Biology 207:869-879.

De Margerie E, Sanchez S, Cubo J, Castanet J. 2005. Torsional resistance as a principal component of the structural design of long bones: comparative multivariate evidence in birds. Anatomical Record 282A:49-66.

De Margerie E, Cubo J, Castanet J. 2002. Bone typology and growth rates: testing and quantifying "Amprino's rule" in the mallard (Anas platyrhynchos). Comptes Rendus Biologies 325:221230.

Martins EP, Hansen TF. 1996. The statistical analysis of interspecific data: a review and evaluation of phylogenetic comparative methods. In: Phylogenies and the Comparative Method in Animal Behavior. New York: Oxford University Press, 22-75. 
520 Martins EP, Hansen TF. 1997. Phylogenies and the comparative method: a general approach to incorporating phylogenetic information into the analysis of interspecific data. American

Muijres FT, Johansson LC, Bowlin MS, Winter Y, Hedenström A. 2012. Comparing aerodynamic efficiency in birds and bats suggests better flight performance in birds. PLoS ONE 7:e37335.

Nagy KA. 2005. Field metabolic rate and body size. Journal of Experimental Biology 208:1621-1625.

Nagy K, Girard I, Brown T. 1999. Energetics of free-ranging mammals, reptiles, and birds. Annual review of nutrition 19:247-277.

Norberg UM. 1994. Wing design, flight performance, and habitat use in bats. In: Ecological Morphology: Integrative Organismal Biology. Chicago, Illinois: University of Chicago Press, $205-239$.

Norberg UML, Norberg RÅ. 2012. Scaling of wingbeat frequency with body mass in bats and limits to maximum bat size. The Journal of Experimental Biology 215:711-722.

Norberg UM, Rayner JMV. 1987. Ecological morphology and flight in bats (Mammalia; Chiroptera): wing adaptations, flight performance, foraging strategy and echolocation. Philosophical Transactions of the Royal Society of London. B, Biological Sciences 316:335-427.

Nunn CL, Barton RA. 2001. Comparative methods for studying primate adaptation and allometry. Evolutionary Anthropology 10:81-98. 
544 Padian K. 2013. Why study the bone microstructure of fossil tetrapods? In: Bone Histology of Fossil

545

546

547

548

549

550

551

552

553

554

555

556

557

558

559

560

561

562

563

564

565

566 Tetrapods: Advancing Methods, Analysis, and Interpretation. Berkeley, California: University of California Press, 1-11.

Papadimitriou HM, Swartz SM, Kunz TH. 1996. Ontogenetic and anatomic variation in mineralization of the wing skeleton of the Mexican free-tailed bat, Tadarida brasiliensis. Journal of Zoology 240:411-426.

Paradis E, Claude J, Strimmer K. 2004. APE: analyses of phylogenetics and evolution in R language. Bioinformatics 20:289-290.

R Development Team. 2014. R: A language and environment for statistical computing. Vienna, Austria: R Foundation for Statistical Computing.

De Ricqlès AJ, Meunier FJ, Castanet J, Francillon-Vieillot H. 1991. Comparative microstructure of bone. In: Hall BK ed. Bone, Volume 3: Bone Matrix and Bone Specific Products. Boston: CRC Press, $1-78$.

Ross MH, Pawlina W. 2011. Histology: a Text and Atlas: with Correlated Cell and Molecular Biology. Baltimore, Maryland: Lippincott Williams \& Wilkins.

Ruff CB. 2000. Body size, body shape, and long bone strength in modern humans. Journal of Human Evolution 38:269-290.

Ruff CB. 2002. Long bone articular and diaphyseal structure in old world monkeys and apes. I: Locomotor effects. American Journal of Physical Anthropology 119:305-342.

Ruff CB, Burgess ML, Bromage TG, Mudakikwa A, McFarlin SC. 2013. Ontogenetic changes in limb bone structural proportions in mountain gorillas (Gorilla beringei beringei). Journal of Human Evolution 65:693-703.

Samuels ML, Witmer JA. 1999. Statistics for the Life Sciences. Upper Saddle River: Prentice-Hall, Inc. 
567 Savage VM, Gillooly J, Woodruff W, West G, Allen A, Enquist B, Brown J. 2004. The predominance of quarter power scaling in biology. Functional Ecology 18:257-282.

569 570

Schmidt-Nielsen K. 1984. Scaling: Why is animal size so important?. New York, New York: Cambridge University Press.

Seymour RS, Smith SL, White CR, Henderson DM, Schwarz-Wings D. 2012. Blood flow to long bones indicates activity metabolism in mammals, reptiles and dinosaurs. Proceedings of the Royal Society B 279:451-456.

Simons ELR, Hieronymus TL, O'Connor PM. 2011. Cross sectional geometry of the forelimb skeleton and flight mode in pelecaniform birds. Journal of Morphology 272:958-971.

Simons ELR, O’Connor PM. 2012. Bone laminarity in the avian forelimb skeleton and its relationship to flight mode: testing functional interpretations. The Anatomical Record 295:386-396.

Skedros JG, Hunt KJ. 2004. Does the degree of laminarity correlate with site specific differences in collagen fibre orientation in primary bone? An evaluation in the turkey ulna diaphysis. Journal of Anatomy 205:121-134.

Starck JM, Ricklefs RE. 1998. Avian growth rate data set. In: Avian Growth and Development. Evolution within the Altricial-precocial Spectrum. New York, New York: Oxford University Press, 381-423.

Stock JT, Shaw CN. 2007. Which measures of diaphyseal robusticity are robust? A comparison of external methods of quantifying the strength of long bone diaphyses to cross-sectional geometric properties. American Journal of Physical Anthropology 134:412-423.

Swartz SM, Bennett MB, Carrier DR. 1992. Wing bone stresses in free flying bats and the evolution of skeletal design for flight. Nature 359:726-729.

Swartz SM, Middleton KM. 2008. Biomechanics of the bat limb skeleton: scaling, material properties and mechanics. Cells Tissues Organs 187:59-84. 
591 Teeling EC, Springer MS, Madsen O, Bates P, O’Brien SJ, Murphy WJ. 2005. A molecular phylogeny

592

593

594

595

596

597

598

599

600

601

602

603

604

605

606

607

608

609

610

611

612

613

for bats illuminates biogeography and the fossil record. Science 307:580-584.

Tsagkogeorga G, Parker J, Stupka E, Cotton JA, Rossiter SJ. 2013. Phylogenomic analyses elucidate the evolutionary relationships of bats. Current Biology 23:2262-2267.

Voigt C, Kelm D, Visser GH. 2006. Field metabolic rates of phytophagous bats: do pollination strategies of plants make life of nectar-feeders spin faster? Journal of Comparative Physiology $B$ 176:213-222.

Voigt CC, Lewanzik D. 2011. Trapped in the darkness of the night: thermal and energetic constraints of daylight flight in bats. Proceedings of the Royal Society B 278:2311-2317.

Werning S. 2013. Osteohistological differences between marsupials and placental mammals reflect both growth rates and life history strategies. Integrative and Comparative Biology 53:E224E224.

Williams B, Waddington D, Murray DH, Farquharson C. 2004. Bone strength during growth: influence of growth rate on cortical porosity and mineralization. Calcified Tissue International 74:236245.

Winter Y, von Helversen O. 1998. The energy cost of flight: do small bats fly more cheaply than birds? Journal of Comparative Physiology B 168:105-111.

Young JW, Fernández D, Fleagle JG. 2010. Ontogeny of long bone geometry in capuchin monkeys (Cebus albifrons and Cebus paella): implications for locomotor development and life history. Biology Letters 6:197-200.

Zullinger EM, Ricklefs RE, Redford KH, Mace GM. 1984. Fitting sigmoidal equations to mammalian growth curves. Journal of Mammalogy 65:607-636. 
1

Variation in vascular canal orientation with skeletal element and growth rate in the chicken.

As seen in transverse section, the humerus, ulna, and femur (A) contain abundant laminar bone, which consists mainly of circumferential vascular canals. The radius (B) shows predominately longitudinal vascular canals. A femur from an individual selected for rapid growth (C) contains an abundance of radial canals. In each panel, periosteal surface points up. Scale bars $=200 \mu \mathrm{m}$. 

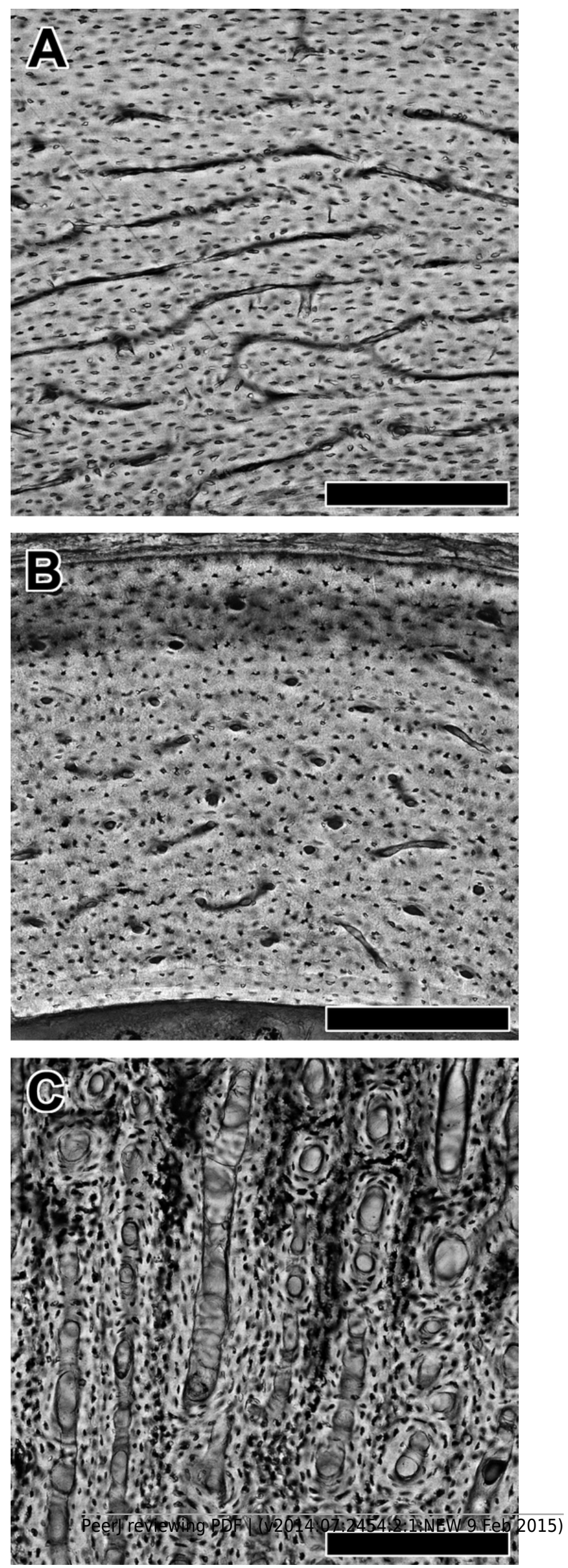
2

Histology of humeri in sampled bats ordered by ascending body mass.

Non-polarized imagery reveals avascular to poorly vascularized compacta. Representative views are from the anterior octant of (A) Rhinolophus lepidus, (B) Macrotus californicus, (C) Phyllostomus discolor, (D) Noctilio leporinus, (E) Rousettus leschenaultii, and (F) Pteropus vampyrus. Periosteal surface points up in each panel. Scale bar equals (A) $150 \mu \mathrm{m}$, (B) 200 $\mu \mathrm{m}$, (C) $300 \mu \mathrm{m}$, (D\& E) $400 \mu \mathrm{m}$, and (F) $800 \mu \mathrm{m}$. Digital slides are available at http://paleohistology.appspot.com.
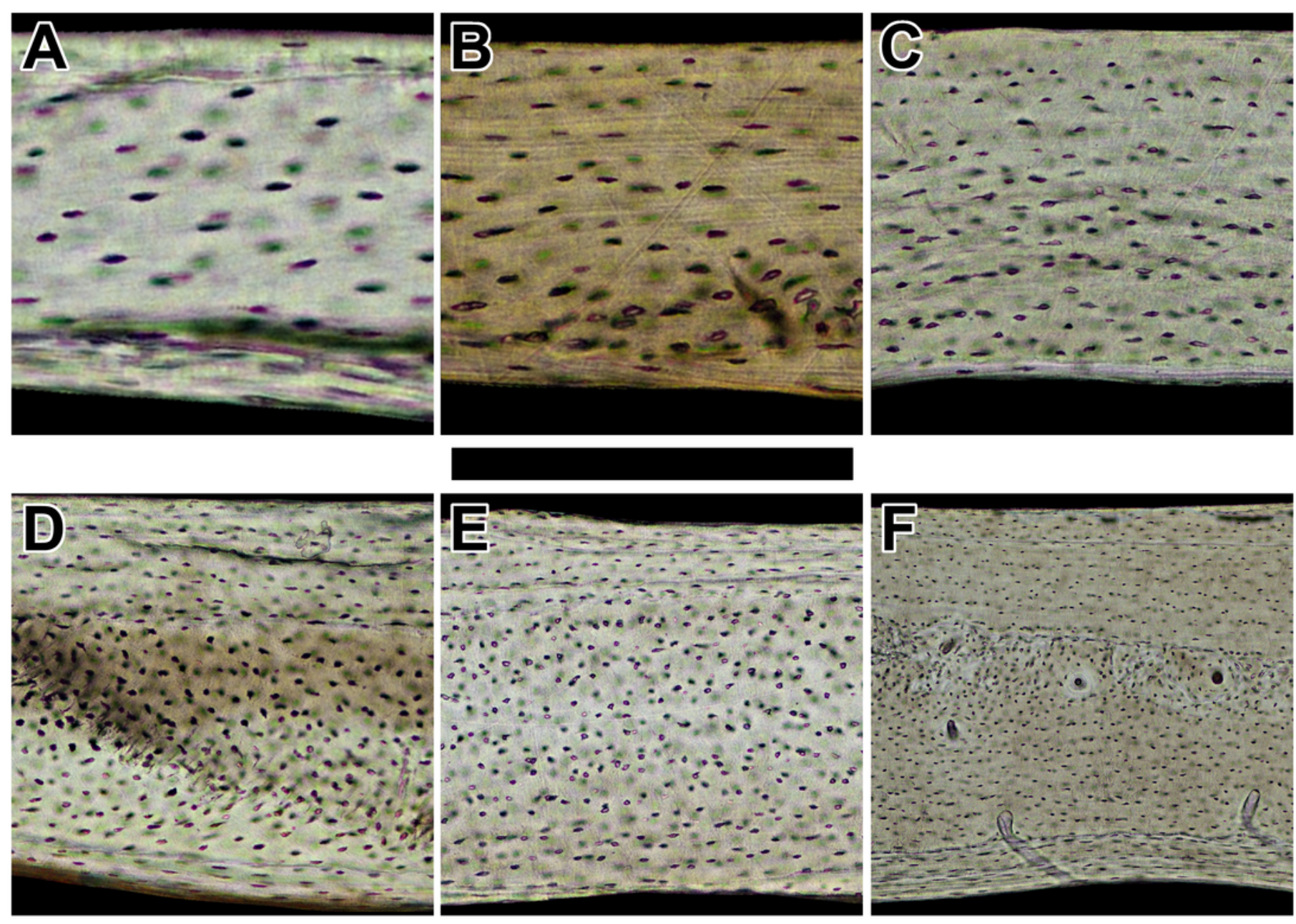


\section{3}

Histology of humeri in sampled birds ordered by ascending body mass.

Representative views are from the cranial octant of (A) Phalaenoptilus nuttallii, (B) Nothura darwinii, (C) Crypturellus boucardi, (D) Crypturellus cinnamomeus, (E) Columba livia, (F) Nothoprocta cinerascens, (G) Nothocercus nigrocapillus, (H) Eudromia elegans, and (I) Tinamus major. Periosteal surface points up in each panel, and a noticeable external fundamental system occurs in both (G) and (I). Scale bar equals (A) $300 \mu \mathrm{m},(B, C, \& E) 400$ $\mu \mathrm{m},(\mathrm{F} \& \mathrm{G}) 480 \mu \mathrm{m},(\mathrm{D} \& \mathrm{I}) 600 \mu \mathrm{m}$, and (H) $800 \mu \mathrm{m}$. Digital slides are available at http://paleohistology.appspot.com. 

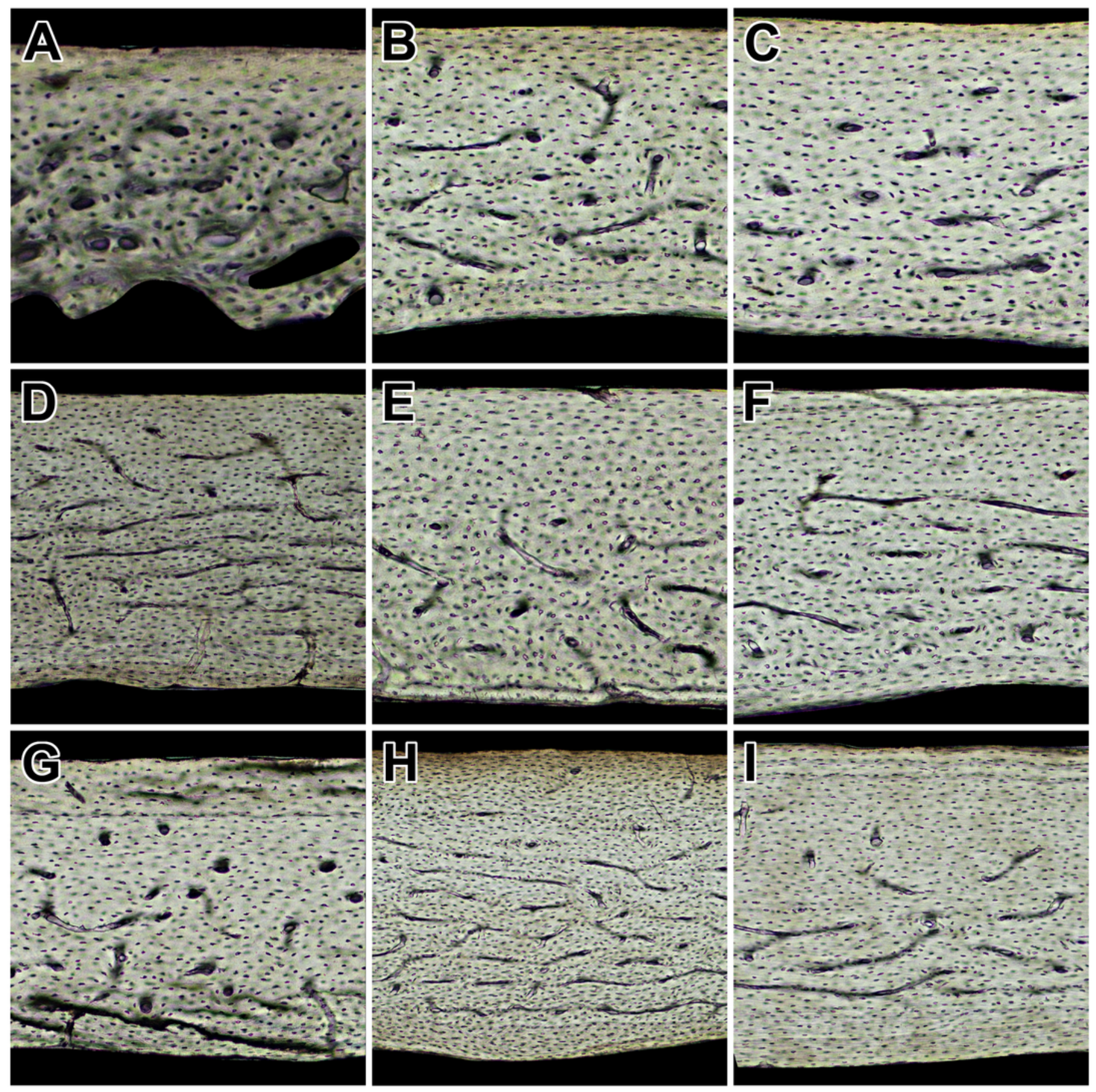


\section{4}

Interspecific scaling of mass-specific field metabolic rate (FMR) in bats and birds.

Bat and bird data points are omitted for clarity. Shaded regions are $95 \%$ confidence bands. Representative views of histology from avian [(A) Phalaenoptilus nuttallii, (B) Nothura darwinii, (C) Tinamus major] and chiropteran [(D) Phyllostomus discolor, (E) Rousettus leschenaultii, (F) Pteropus vampyrus] humeri suggest that the vascular dichotomy between bats and birds is not related to mass-specific FMR. 


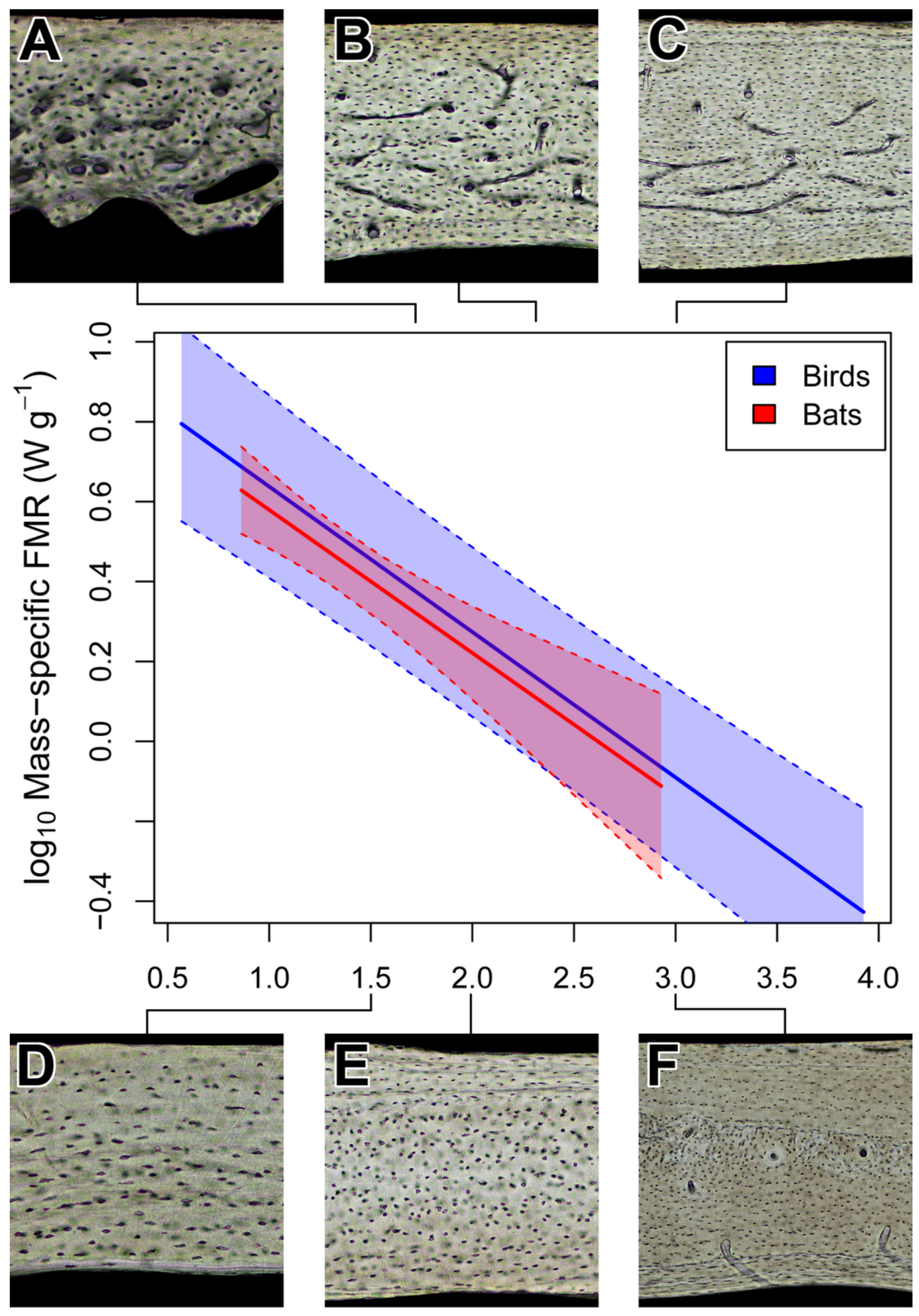




\section{5}

Interspecific scaling of somatic relative growth rate (RGR) in bats and birds.

Shaded regions are $95 \%$ confidence bands. Representative views of histology from avian [(A)

Phalaenoptilus nuttallii, (B) Nothura darwinii, (C) Tinamus major] and chiropteran [(D)

Phyllostomus discolor, (E) Rousettus leschenaultii, (F) Pteropus vampyrus] humeri suggest

that the vascular dichotomy between bats and birds may be a reflection of differences in growth rate. 

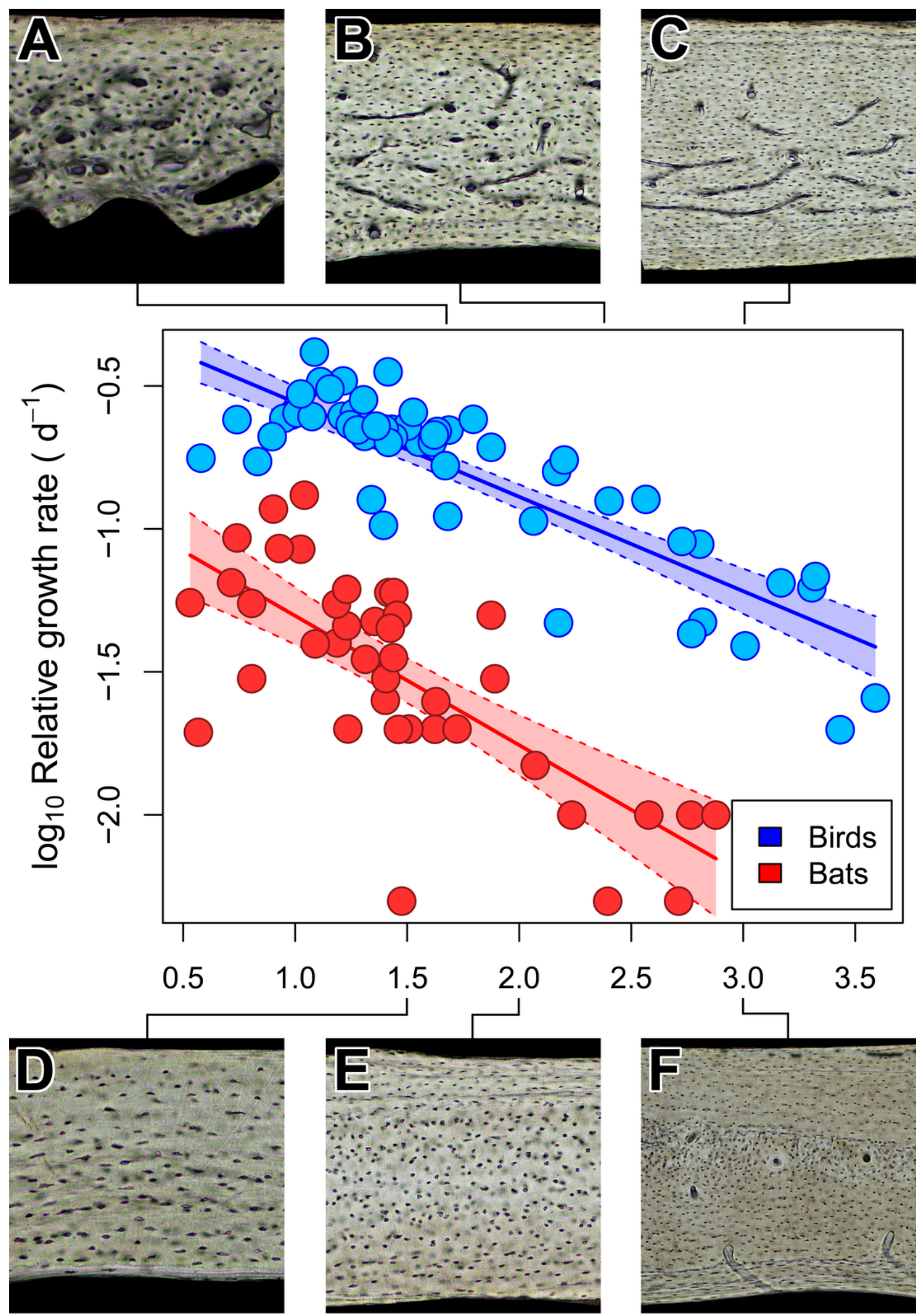
6

Isometric scaling of polar section modulus $\left(Z_{p}\right)$ in humeri of bats and birds.

Shaded regions are $95 \%$ confidence bands. Representative views of histology from

chiropteran [(A) Phalaenoptilus nuttallii, (B) Nothura darwinii, (C) Tinamus major] and avian

[(D) Phyllostomus discolor, (E) Rousettus leschenaultii, (F) Pteropus vampyrus] humeri

suggest that the vascular dichotomy has little impact on the torsional rigidity of humeri. 

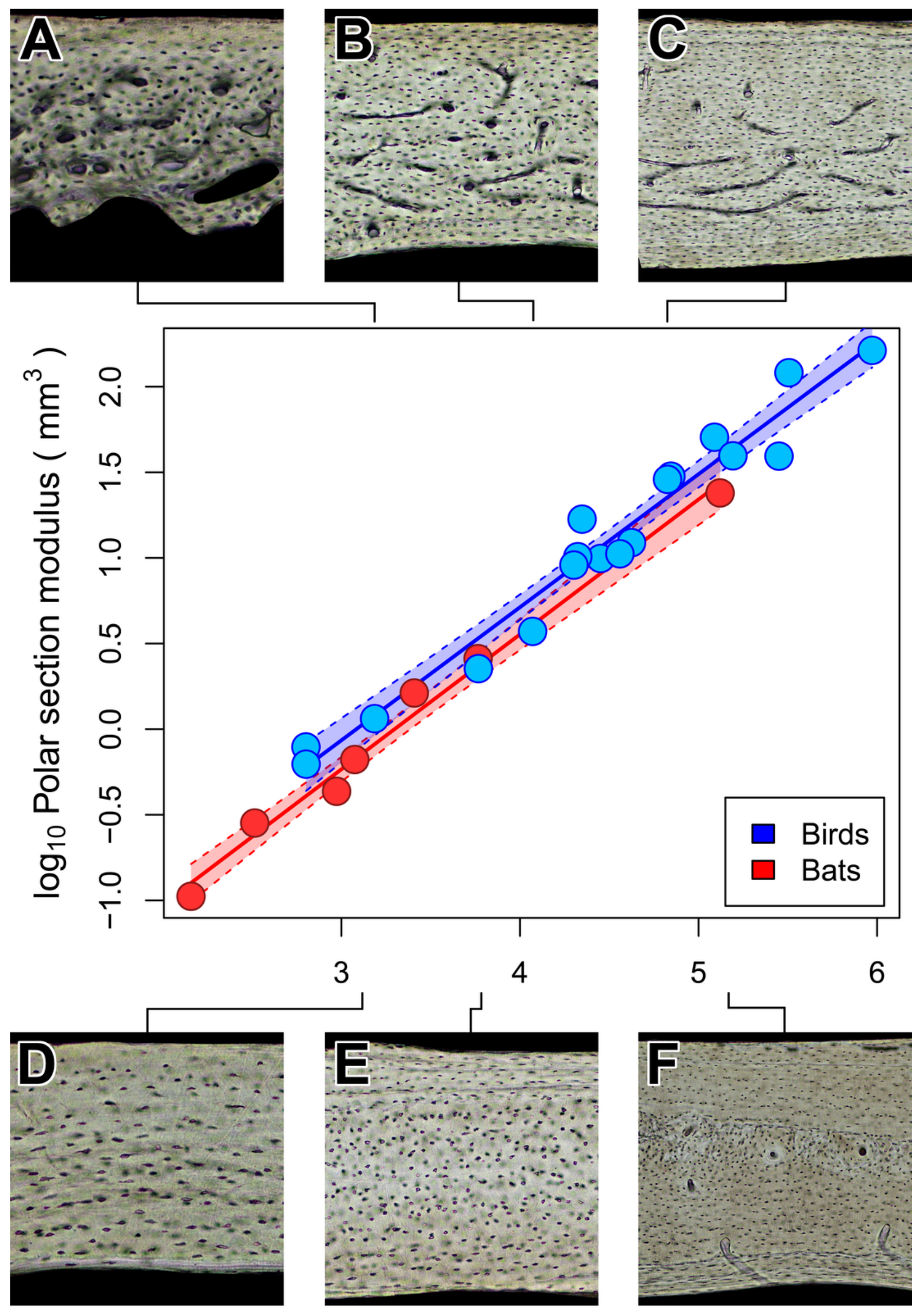

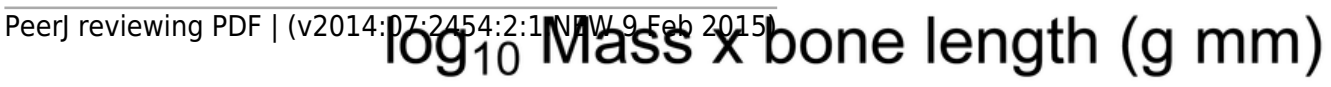


Table $\mathbf{1}_{\text {(on next page) }}$

Properties of analyzed specimens.

Abbreviations: CMNH, Carnegie Museum of Natural History; MWU, Midwestern University; NMNH, Smithsonian Institution National Museum of Natural History; OUVC, Ohio University Vertebrate Collections; UA, University of Arizona; UF, Florida Museum of Natural History; LI, laminarity index; ${ }^{*}$, known mass of individual; $Z_{p}$, polar section modulus. 
Table 1 Properties of analyzed specimens.

\begin{tabular}{|c|c|c|c|c|c|}
\hline Taxon & Specimen & Mass (g) & $\begin{array}{c}\text { Humeral } \\
\text { length }(\mathrm{mm})\end{array}$ & LI $(95 \% \mathrm{CI})$ & $Z_{p}\left(\mathbf{m m}^{3}\right)$ \\
\hline \multicolumn{6}{|l|}{ Bats } \\
\hline $\begin{array}{l}\text { Rhinolophus } \\
\text { lepidus }\end{array}$ & pers. coll. H1-2 & 6 & 24 & 0 & 0.163 \\
\hline $\begin{array}{l}\text { Macrotus } \\
\text { californicus }\end{array}$ & UA 3767 H1-2 & 12 & 28 & 0 & 0.284 \\
\hline Myotis myotis & $\begin{array}{l}\text { Meier et al., } \\
2013\end{array}$ & 29 & 33 & $\mathrm{n} / \mathrm{a}$ & 0.435 \\
\hline $\begin{array}{l}\text { Phyllostomus } \\
\text { discolor }\end{array}$ & UA $16197 \mathrm{H1}-1$ & 34 & 35 & 0 & 0.921 \\
\hline Noctilio leporinus & UA 15743 H1-2 & 61 & 42 & 0 & 2.426 \\
\hline $\begin{array}{l}\text { Rousettus } \\
\text { leschenaultii }\end{array}$ & pers. coll. H1-2 & 108 & 54 & 0 & 3.312 \\
\hline Pteropus vampyrus & pers. coll. H1-2 & 1024 & 129 & 0 & 30.586 \\
\hline \multicolumn{6}{|l|}{ Birds } \\
\hline $\begin{array}{l}\text { Oceanodroma } \\
\text { tethys }\end{array}$ & NMNH 614194 & 23 & 28 & $\mathrm{n} / \mathrm{a}$ & 0.627 \\
\hline $\begin{array}{l}\text { Oceanites } \\
\text { oceanicus }\end{array}$ & CMNH 7752 & 29 & 22 & $\mathrm{n} / \mathrm{a}$ & 0.790 \\
\hline $\begin{array}{l}\text { Phalaenoptilus } \\
\text { nuttallii }\end{array}$ & MWU 264 H1-1 & 48 & 32 & $\begin{array}{c}0.259 \\
(0.082) \\
\end{array}$ & 1.156 \\
\hline Bulweria bulwerii & NMNH 556263 & 99 & 59 & $\mathrm{n} / \mathrm{a}$ & 2.265 \\
\hline Nothura darwinii & UF $22260 \mathrm{H} 1-2$ & 274 & 43 & $\begin{array}{c}0.316 \\
(0.055)\end{array}$ & 4.762 \\
\hline $\begin{array}{l}\text { Crypturellus } \\
\text { boucardi }\end{array}$ & UF 44840 H1-1 & 418 & 48 & $\begin{array}{c}0.211 \\
(0.057) \\
\end{array}$ & 10.238 \\
\hline $\begin{array}{l}\text { Crypturellus } \\
\text { cinnamomeus }\end{array}$ & UA 8699 H2-1 & 422 & 50 & $\begin{array}{c}0.388 \\
(0.047)\end{array}$ & 12.156 \\
\hline Columba livia & MWU 256 H1-2 & $455^{*}$ & 49 & $\begin{array}{c}0.063 \\
(0.024)\end{array}$ & 11.801 \\
\hline $\begin{array}{l}\text { Nothoprocta } \\
\text { cinerascens }\end{array}$ & UF 38951 H1-2 & $480^{*}$ & 59 & $\begin{array}{c}0.462 \\
(0.048) \\
\end{array}$ & 12.921 \\
\hline $\begin{array}{l}\text { Calonectris } \\
\text { diomedea }\end{array}$ & OUVC 10438 & 535 & 125 & 0.070 & 28.887 \\
\hline $\begin{array}{l}\text { Nothocercus } \\
\text { nigrocapillus }\end{array}$ & UF 43432 H1-2 & $605^{*}$ & 60 & $\begin{array}{c}0.115 \\
(0.037)\end{array}$ & 11.896 \\
\hline Eudromia elegans & UF 22257 H1-1 & 680 & 62 & $\begin{array}{c}0.578 \\
(0.052)\end{array}$ & 14.756 \\
\hline Tinamus major & UF 44828 H1-2 & 960 & 73 & $\begin{array}{c}0.316 \\
(0.044)\end{array}$ & 34.868 \\
\hline Buteo jamaicensis & OUVC 10506 & 1126 & 109 & 0.703 & 50.879 \\
\hline
\end{tabular}




\begin{tabular}{|l|l|c|c|c|c|}
\hline Anhinga anhinga & OUVC 10432 & 1235 & 126 & 0.233 & 39.635 \\
\hline $\begin{array}{l}\text { Phalacrocorax } \\
\text { auritus }\end{array}$ & OUVC 10482 & 1960 & 144 & 0.390 & 39.449 \\
\hline Cathartes aura & OUVC 9648 & 2006 & 160 & 0.376 & 121.185 \\
\hline $\begin{array}{l}\text { Pelecanus } \\
\text { occidentalis }\end{array}$ & OUVC 10484 & 3438 & 273 & 0.478 & 163.645 \\
\hline
\end{tabular}

Abbreviations: CMNH, Carnegie Museum of Natural History; MWU, Midwestern University;

NMNH, Smithsonian Institution National Museum of Natural History; OUVC, Ohio University

Vertebrate Collections; UA, University of Arizona; UF, Florida Museum of Natural History; LI, laminarity index; *, known mass of individual; $Z_{\mathrm{p}}$, polar section modulus. 
Table 2 (on next page)

Scaling of $\log 10$ (mass) and $\log 10$ (mass-specific field metabolic rate).

Abbreviations follow text. Models selected for interspecific comparison in bold. 
Table 2 Scaling of $\log 10$ (mass) and $\log 10$ (mass-specific field metabolic rate).

\begin{tabular}{|c|c|c|c|c|c|}
\hline Taxon & Model & Slope & $95 \% \mathrm{CI}$ & Intercept & 95\% CI \\
\hline \multirow[t]{4}{*}{ Bats $(n=14)$} & $\begin{array}{l}\text { OLS }\left(\mathrm{AIC}_{\mathrm{c}}=-7.0 ; \text { random }\right. \\
\text { residuals) }\end{array}$ & -0.358 & $\begin{array}{l}-0.515 \\
-0.201\end{array}$ & 0.938 & $\begin{array}{c}0.702 \\
1.173\end{array}$ \\
\hline & $\begin{array}{l}\text { PGLS-BM }\left(\mathrm{AIC}_{\mathrm{c}}=7.1 ;\right. \\
\text { random residuals) }\end{array}$ & -0.405 & $\begin{array}{l}-0.615 \\
-0.195\end{array}$ & 0.996 & $\begin{array}{l}0.564, \\
1.427\end{array}$ \\
\hline & $\begin{array}{l}\text { PGLS-OU }\left(\alpha=1.1 ; \mathrm{AIC}_{\mathrm{c}}=\right. \\
3.8 ; \text { random residuals })\end{array}$ & -0.358 & $\begin{array}{l}-0.499 \\
-0.217\end{array}$ & 0.938 & $\begin{array}{l}0.725, \\
1.150\end{array}$ \\
\hline & $\begin{array}{l}\text { PGLS-OU }\left(\alpha=1.8 ; \mathrm{AIC}_{\mathrm{c}}=\right. \\
3.8 ; \text { random residuals })\end{array}$ & -0.358 & $\begin{array}{l}-0.499 \\
-0.217\end{array}$ & 0.938 & $\begin{array}{l}0.725, \\
1.150\end{array}$ \\
\hline \multirow[t]{4}{*}{ Birds $(n=86)$} & $\begin{array}{l}\mathrm{OLS}\left(\mathrm{AIC}_{\mathrm{c}}=-44.5 ; \text { random }\right. \\
\text { residuals) }\end{array}$ & -0.356 & $\begin{array}{l}-0.406 \\
-0.305 \\
\end{array}$ & 1.066 & $\begin{array}{l}0.967, \\
1.164\end{array}$ \\
\hline & $\begin{array}{l}\text { PGLS-BM }\left(\mathrm{AIC}_{\mathrm{c}}=-73.7 ;\right. \\
\text { random residuals) }\end{array}$ & -0.364 & $\begin{array}{l}-0.444, \\
-0.284\end{array}$ & 1.002 & $\begin{array}{l}0.732 \\
1.271\end{array}$ \\
\hline & $\begin{array}{l}\text { PGLS-OU }\left(\alpha=0 ; \mathrm{AIC}_{\mathrm{c}}=\right. \\
-72.0 ; \text { random residuals })\end{array}$ & -0.367 & $\begin{array}{l}-0.446 \\
-0.289\end{array}$ & 1.019 & $\begin{array}{l}0.546, \\
1.491\end{array}$ \\
\hline & $\begin{array}{l}\text { PGLS-OU }\left(\alpha=10 ; \mathrm{AIC}_{\mathrm{c}}=\right. \\
-30.9 ; \text { random residuals })\end{array}$ & -0.356 & $\begin{array}{l}-0.405, \\
-0.306\end{array}$ & 1.066 & $\begin{array}{l}0.969 \\
1.163\end{array}$ \\
\hline
\end{tabular}

Abbreviations follow text. Models selected for interspecific comparison in bold. 


\section{Table 3(on next page)}

Scaling of log10(asymptotic mass) and log10(somatic relative growth rate).

Abbreviations follow text. Models selected for interspecific comparison in bold. 
Table 3 Scaling of $\log 10$ (asymptotic mass) and $\log 10$ (somatic relative growth rate).

\begin{tabular}{|c|c|c|c|c|c|}
\hline Taxon & Model & Slope & $95 \%$ CI & Intercept & $95 \%$ CI \\
\hline \multirow[t]{4}{*}{ Bats $(n=40)$} & $\begin{array}{l}\mathrm{OLS}\left(\mathrm{AIC}_{\mathrm{c}}=8.3 ; \text { random }\right. \\
\text { residuals })\end{array}$ & -0.452 & $\begin{array}{l}-0.590 \\
-0.314 \\
\end{array}$ & -0.852 & $\begin{array}{l}-1.070 \\
-0.634 \\
\end{array}$ \\
\hline & $\begin{array}{l}\text { PGLS-BM }\left(\mathrm{AIC}_{\mathrm{c}}=10.1 ; \text { non- }\right. \\
\text { random residuals })\end{array}$ & -0.258 & $\begin{array}{l}-0.455 \\
-0.062 \\
\end{array}$ & -1.169 & $\begin{array}{l}-1.564 \\
-0.775 \\
\end{array}$ \\
\hline & $\begin{array}{l}\text { PGLS-OU }\left(\alpha=0.02 ; \mathrm{AIC}_{\mathrm{c}}=9.3 ;\right. \\
\text { non-random residuals) }\end{array}$ & -0.306 & $\begin{array}{l}-0.491 \\
-0.120 \\
\end{array}$ & -1.099 & $\begin{array}{l}1.419 \\
-0.779 \\
\end{array}$ \\
\hline & $\begin{array}{l}\text { PGLS-OU }\left(\alpha=1.5 ; \text { AIC }_{c}=18.6 ;\right. \\
\text { random residuals) }\end{array}$ & -0.452 & $\begin{array}{l}-0.585 \\
-0.319 \\
\end{array}$ & -0.852 & $\begin{array}{l}-1.063, \\
-0.641 \\
\end{array}$ \\
\hline \multirow[t]{4}{*}{ Birds $(n=56)$} & $\begin{array}{l}\text { OLS }\left(\mathrm{AIC}_{\mathrm{c}}=-46.2 ; \text { random }\right. \\
\text { residuals) }\end{array}$ & -0.330 & $\begin{array}{l}-0.384 \\
-0.276\end{array}$ & -0.227 & $\begin{array}{l}-0.329 \\
-0.126\end{array}$ \\
\hline & $\begin{array}{l}\text { PGLS-BM }\left(\mathrm{AIC}_{\mathrm{c}}=-58.5 ; \text { non- }\right. \\
\text { random residuals })\end{array}$ & -0.290 & $\begin{array}{l}-0.364, \\
-0.215 \\
\end{array}$ & -0.425 & $\begin{array}{l}-0.675 \\
-0.174 \\
\end{array}$ \\
\hline & $\begin{array}{l}\text { PGLS-OU }\left(\alpha=0 ; \text { AIC }_{\mathrm{c}}=-57.4 ;\right. \\
\text { non-random residuals })\end{array}$ & -0.287 & $\begin{array}{l}-0.358 \\
-0.217 \\
\end{array}$ & -0.418 & $\begin{array}{l}-0.756 \\
-0.081 \\
\end{array}$ \\
\hline & $\begin{array}{l}\text { PGLS-OU }\left(\alpha=2.5 ; \mathrm{AIC}_{\mathrm{c}}=\right. \\
-32.8 ; \text { random residuals) }\end{array}$ & $-\mathbf{- 0 . 3 3 0}$ & $\begin{array}{l}-0.383 \\
-0.277 \\
\end{array}$ & -0.227 & $\begin{array}{l}-0.327, \\
-0.128 \\
\end{array}$ \\
\hline
\end{tabular}

Abbreviations follow text. Models selected for interspecific comparison in bold. 


\section{Table 4 (on next page)}

Scaling of $\log 10$ (polar section modulus of humerus) and log10(body mass $x$ humeral length).

Abbreviations follow text. Models selected for interspecific comparison in bold. 
Table 4 Scaling of $\log 10$ (polar section modulus of humerus) and $\log 10$ (body mass $\mathrm{x}$ humeral length).

\begin{tabular}{|c|c|c|c|c|c|}
\hline Taxon & Model & Slope & $95 \%$ CI & Intercept & $95 \%$ CI \\
\hline \multirow[t]{4}{*}{ Bats $(n=7)$} & $\begin{array}{l}\text { OLS }\left(\mathrm{AIC}_{\mathrm{c}}=-1.8 ;\right. \\
\text { random residuals) }\end{array}$ & 0.788 & $0.688,0.889$ & -2.599 & $-2.941,-2.257$ \\
\hline & $\begin{array}{l}\text { PGLS-BM }\left(\mathrm{AIC}_{\mathrm{c}}=23.9 ;\right. \\
\text { random residuals) }\end{array}$ & 0.769 & $0.687,0.851$ & -2.550 & $-2.834,-2.266$ \\
\hline & $\begin{array}{l}\text { PGLS-OU }\left(\alpha=0 ; \mathrm{AIC}_{\mathrm{c}}=\right. \\
25.9 ; \text { random residuals })\end{array}$ & 0.771 & $0.689,0.854$ & -2.556 & $-3.016,-2.097$ \\
\hline & $\begin{array}{l}\text { PGLS-OU }\left(\alpha=1 ; \mathrm{AIC}_{\mathrm{c}}=\right. \\
26.1 ; \text { random residuals })\end{array}$ & 0.789 & $0.712,0.865$ & -2.599 & $-2.860,-2.338$ \\
\hline \multirow[t]{4}{*}{ Birds $(\mathrm{n}=18)$} & $\begin{array}{l}\text { OLS }\left(\mathrm{AIC}_{\mathrm{c}}=-13.5 ;\right. \\
\text { random residuals) }\end{array}$ & 0.778 & $0.695,0.860$ & -2.397 & $-2.770,-2.024$ \\
\hline & $\begin{array}{l}\text { PGLS-BM }\left(\mathrm{AIC}_{\mathrm{c}}=\right. \\
-1.6 ; \text { random residuals })\end{array}$ & 0.792 & $0.712,0.871$ & -2.445 & $-2.840,-2.050$ \\
\hline & $\begin{array}{l}\text { PGLS-OU }\left(\alpha=0.3 ; \mathrm{AIC}_{\mathrm{c}}\right. \\
=-1.5 ; \text { random residuals })\end{array}$ & 0.777 & $0.701,0.853$ & -2.397 & $-2.742,-2.052$ \\
\hline & $\begin{array}{l}\text { PGLS-OU }\left(\alpha=1 ; \mathrm{AIC}_{\mathrm{c}}=\right. \\
-1.5 ; \text { random residuals })\end{array}$ & 0.777 & $0.701,0.853$ & -2.397 & $-2.742,-2.052$ \\
\hline
\end{tabular}

Abbreviations follow text. Models selected for interspecific comparison in bold. 